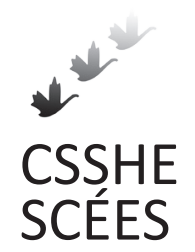

Canadian Journal of Higher Education Revue canadienne d'enseignement supérieur

Volume 44, No. 2, 2014, pages 135 - 151

\title{
Exploring levels of student-athlete burnout at two Canadian universities
}

Nicole Dubuc-Charbonneau, Natalie Durand-Bush, and Tanya Forneris University of Ottawa

\begin{abstract}
The purpose of the current study was to examine the levels of burnout among student-athletes at two Canadian universities and to investigate whether there were significant differences related to gender, sport, year of university sport participation, academic year, and academic program. Burnout was measured by administering Raedeke and Smith's (2001) Athlete Burnout Questionnaire to 145 student-athletes from various sports. Overall, $1.4 \%$ of the student-athletes had elevated burnout scores on all three subscales, and 17\% scored high on two of the three subscales. No significant differences emerged with regards to year of varsity sport participation, academic year, or program. However, women had significantly higher levels of emotional and physical exhaustion than men. Significant differences also emerged in relation to levels of emotional and physical exhaustion, and of sport devaluation, when comparing various sports.
\end{abstract}

\section{Résumé}

Le but de cette étude était d'évaluer le niveau d'épuisement d'étudiants athlètes fréquentant deux universités canadiennes et de déterminer s'il y avait des différences significatives liées au sexe, au sport, au nombre d'années de participation au sport universitaire, ainsi qu'à l'année universitaire et au programme d'étude. L'épuisement a été mesuré en distribuant le « Athlete Burnout Questionnaire » (Raedeke \& Smith, 2001) à 145 étudiants athlètes universitaires de différentes disciplines sportives. En somme, 1,4 \% des participants ont affiché des scores élevés sur chacune des trois sous-échelles et $17 \%$ ont fait de même sur deux d'entre elles. Aucune différence marquée n'a été identifiée quant au nombre d'années de participation au sport universitaire, ni à l'année universitaire ou au type de programme d'étude. Cependant, les femmes ont affiché un niveau d'épuisement émotif et physique significativement plus 
élevé que celui des hommes. En outre, on a noté des différences marquées en comparant les sports entre eux en ce qui a trait au niveau d'épuisement émotif et physique et au niveau de dévalorisation des disciplines.

\section{Introduction}

University sports offer an opportunity for athletes to remain involved in competitive sport while pursuing a post-secondary education. In fact, for many athletes, participating in university sports will represent the peak of their competitive careers. Playing on a college or university team can provide numerous health and social benefits (Miller \& Kerr, 2002). A survey comparing over 2000 athletes from various sports with non-athletes revealed that athletes have higher levels of psychological well-being than non-athletes (Aries, McCarthy, Salovey, \& Banaji, 2004). Despite these advantages, factors such as pressure to succeed, extensive travelling, and intense training schedules can cause stress and overshadow the positive outcomes associated with their sport participation (Gould \& Whitley, 2009). In addition to sport-related stressors, student-athletes face various academic and social demands (e.g., assignments, examinations, development of friendships) and must meet the constant challenge of maintaining a desired level of performance in both sport and academic contexts (Gustafsson, Hassmén, Kenttä, \& Johansson, 2008; Miller \& Kerr, 2002). It is suggested that the physiological, emotional, and psychological stress that can result from an athlete's inability to cope with demands can contribute to the development of burnout (Gustafsson, Kenttä, \& Hassmén, 2011; Raedeke \& Smith, 2004).

\section{Conceptualizations of Burnout in Sport}

Research on burnout stems from the occupational literature, and although Freudenberger (1974) was the first to report that workers could "burn out," Maslach and Jackson (1981) offered the first and now most common conceptualization of workplace burnout. Their research indicates that burnout has three distinct components: (a) emotional exhaustion, (b) depersonalization, and (c) a sense of reduced accomplishment. In the context of sport, Raedeke's (1997) athlete-specific definition of burnout is the one that is most consistent with Maslach and Jackson's (1981) original workplace conceptualization. According to Raedeke, athlete burnout can be defined as a condition characterized by emotional and physical exhaustion, sport devaluation, and reduced personal accomplishment. The constructs within this definition have since been utilized to develop the Athlete Burnout Questionnaire (ABQ; Raedeke \& Smith, 2001), which is currently the most prominently employed tool to measure athlete burnout. The ABQ was selected to assess burnout in the current study.

Smith's (1986) sport-specific, stress-based burnout model is also of relevance in this discussion of conceptualizations of burnout. Congruent with the work of Lazarus (1966, 1982), Smith postulated that stress is the result of athletes' perceived imbalance between the demands they face and the resources and abilities they possess to meet these demands. Furthermore, stress can lead to many negative responses, such as tension, depression, and fatigue (Smith, 1986). If one is unable to manage chronic negative responses from stress, burnout can develop (Smith, 1986). Smith's sport-specific model was the guiding conceptual framework in the present study. 
Burnout in sport has also been conceptualized from physiological (Kenttä \& Hassmén, 1998; Silva, 1990), organizational (Coakley, 1992; Coakley, 2009), and motivational perspectives (Lemyre, Treasure, \& Roberts, 2006; Perreault, Gaudreau, Lapointe, \& Lacroix, 2007; Raedeke, 1997; Schmidt \& Stein, 1991). While these various conceptualizations have led researchers to postulate different factors that contribute to the development of burnout, commonalities regarding associated symptoms and consequences of burnout have emerged. Specifically, athlete burnout is often linked to increases in fatigue (Cresswell \& Eklund, 2006, 2007), lethargy (Cresswell \& Eklund, 2006; Goodger, Wolfenden, \& Lavallee, 2007), illness (Cresswell \& Eklund, 2006; Gould, Tuffey, Udry, \& Loehr, 1996, 1997), injury (Cresswell \& Eklund 2005, 2006), amotivation (Cresswell \& Eklund, 2005, 2006; Gould et al., 1996; Lemyre et al., 2006), loss of focus (Cresswell \& Eklund, 2006; Goodger et al., 2007; Gould et al., 1996), and self-doubt (Cresswell \& Eklund, 2006; Lemyre, Hall, \& Roberts, 2008). Emotional responses such as frustration (Cresswell \& Eklund, 2006; Goodger et al., 2007; Gould et al., 1996), anger (Coakley, 1992; Smith, 1986), feelings of incompetence (Cresswell \& Eklund, 2007; Goodger et al., 2007), and mood disturbances (Cresswell \& Eklund, 2006; Goodger et al., 2007; Gustafsson et al., 2008) have also emerged as consequences of burnout.

\section{Prevalence of Burnout in Sport}

Although researchers have uncovered various precursors and consequences of burnout, the prevalence of athlete burnout is not as clear. Silva (1990), for example, found that over $60 \%$ of elite athletes in his study experienced "staleness," which, according to overtraining syndrome researchers, can be considered a precursor of burnout (Morgan, Brown, Raglin, O'Conner, \& Ellickson, 1987). Silva (1990) also estimated that burnout was experienced by $47 \%$ of the 68 National Collegiate Athletic Association (NCAA) athletes in his sample. However, these results have to be interpreted with caution, given the lack of validity and reliability of the training stress syndrome model guiding the study and the tool used to measure burnout. Nearly two decades later, Hodge, Lonsdale, and Ng (2008) examined the levels of burnout and motivation (i.e., autonomy, competence, relatedness) of elite male rugby players. Participants were categorized as either low or high burnout, based on their ABQ scores (Raedeke \& Smith, 2001). While the group with high burnout scores reported significantly lower autonomy and competence scores than the group with low levels of burnout, relatedness scores did not differ across groups. Overall, Hodge and colleagues found that only six of the 133 rugby players (4\%) had high levels of burnout. Interestingly, the cut-off scores for athletes in the high burnout group were 3.0 on the emotional and physical exhaustion and sport devaluation subscales and 2.7 on the reduced accomplishment subscale. These values were determined using Raedeke's (1997) cluster analysis data, the Maslach Burnout Inventory-General Survey (MBI-GS) cut-off values for high employee burnout (Maslach, Jackson, \& Leiter, 1996), and tentative classifications offered by Eklund and Cresswell (2007). The lower cut-off criterion for the reduced personal accomplishment subscale (2.7) was determined based on the cut-off criteria from the MBI-GS (Maslach et al., 1996) and the finding that many participants within the high burnout group in Raedeke's (1997) cluster analysis had reduced accomplishment scores lower than three (Hodge et al., 2008). 
Gustafsson, Kenttä, Hassmén, and Lundqvist (2007) examined the prevalence of burnout among 980 adolescent Swedish athletes ranging in age from 16 to 21 years. Using the Eades Athletic Burnout Inventory (Eades, 1991), Gustafsson and colleagues reported that between 1 and $9 \%$ of female athletes and 1 and $6 \%$ of male athletes indicated high levels of burnout. Specifically, women reported higher levels of negative self-concept of athletic ability as well as emotional and physical exhaustion than their male counterparts, whereas men had slightly higher levels of sport devaluation. Another emerging trend was that the women participating in team sports had lower burnout scores than those participating in individual sports. On the other hand, men competing in team sports had higher burnout scores than those partaking in individual sports (Gustafsson et al., 2007). While a strength of this study was the large sample of athletes surveyed, a limitation was the use of an inventory with "psychometric shortcomings" (Gustafsson et al., 2007, p. 32) that subsequently has rarely been used in the study of burnout in sport.

Supporting these findings but using a different measure, Cremades and colleagues (2008) revealed that among NCAA college athletes, female team-sport athletes reported a higher sense of accomplishment than did female athletes in individual sports, although no team versus individual sport differences were found among male athletes. Furthermore, female athletes had higher levels of emotional and physical exhaustion as well as higher levels of sport devaluation than male athletes. In a more recent study examining gender differences in burnout among individual sport athletes from various national Iranian teams, it was reported that female athletes had significantly higher burnout levels than male athletes on all three of the ABQ subscales (Heidari, 2013). A South African study examining burnout and sport experience among college rugby players highlighted that when comparing a novice group (first season), a somewhat experienced group (one to two years), and an experienced group (minimum of three years), the most experienced athletes had significantly higher sport devaluation scores than the less experienced and novice players. The novice group and the somewhat experienced group did not show differences in burnout scores (Grobbelarr, Malan, Steyn, \& Ellis, 2010).

While the aforementioned studies provide some valuable information, current levels of burnout among Canadian athletes have yet to be assessed, particularly by means of a valid and reliable tool like the ABQ (Raedeke \& Smith, 2001). Another limitation in the literature is that most existing findings have not been replicated or supported by subsequent studies. Hence, more research employing validated measures with additional samples of athletes is warranted.

\section{Stress and Burnout in Academic Settings}

Stress and burnout occur not only in sport but also in academic settings. Interestingly, academic settings in which athletes play the dual role of student-athlete, and in which demands are elevated, have not been the focus of various burnout studies. It is logical to examine student-athletes through the lens of the sport and academic burnout literature, given this double role they play and the different types of stressors they face. The literature pertaining to stress in academia suggests that university students in general experience high levels of stress. For example, a national survey conducted almost a decade ago among 6,282 Canadian undergraduate students revealed that $29 \%$ of them experienced elevated psychological distress (e.g., chronic stress, lack of sleep, loss of confidence, de- 
pression, feelings of incompetence) (Adlaf, Demers, \& Gliksman, 2005). A similar 1998 survey had indicated that distress declined as students progressed through their program of study (Adlaf, Gliksman, Demers, \& Newton-Taylor, 2001). However, this finding was not replicated with the 2004 student population (Adlaf et al., 2005). This decline in stress was also found by Misra and McKean (2000) as well as Rawson, Bloomer, and Kendall (2001), who reported that sophomore students had higher mean levels of stress than juniors within their college student population.

More recently, 53\% of students from six Ontario post-secondary institutions reported feeling overwhelmed with anxiety, and 36\% stated that feelings of depression hindered their day-to-day functioning (American College Health Association, 2009). This growing concern was underscored in a recent report commissioned by the Canadian Association of College and University Student Services, revealing that "mental health issues are identified by students as having the greatest impact on their academic success," and that student mental health should become a top priority for Canadian colleges and universities (MacKean, 2011, p. 6). Still, it is unclear whether or not Canadian university studentathletes, a subset of this population, are more or less at risk of anxiety and reduced health.

In another study conducted with Canadian undergraduate students, Campbell, Svenson, and Jarvis (1992) found that lack of time and of self-discipline were two main contributors to students' perceived elevated stress. Of particular interest to the current investigation, Kimball and Freysinger (2003) reported that lack of autonomy and feelings of isolation were listed as reasons for which undergraduate student-athletes were no longer finding sports to be a source of enjoyment or a vehicle for coping with negative outcomes associated with stress. Instead, they found sports to contribute to their overall levels of stress.

With regards to the literature on burnout in academia, results from a recent study by Salanova, Schaufeli, Martinez, and Breso (2010) revealed that university students who were burned out perceived a significantly higher number of obstacles (e.g., overload, lack of academic support, financial demands) and a lower number of resources (e.g., social support, scholarships, tutoring, access to student services). Salmela-Aro, Noona, Pietikäinen, and Jokela (2008) examined burnout correlates within high school settings, which, based on the aforementioned findings, may also be relevant in university settings. These authors reported that negative school climate was positively correlated with burnout, while support from the school, as well as motivation and encouragement from teachers, were negatively correlated with burnout. Also, when specifically exploring burnout among adolescent student-athletes, Dubuc, Schinke, Eys, Battochio, and Zaichkowsky (2010) found that the negative repercussions associated with elevated stress and burnout can hinder the quality of student-athletes' athletic experiences as well as their academic and personal lives.

Additional burnout studies conducted in the context of academia have focused on college athletes (Lai \& Wiggins, 2003; Lemyre et al., 2006; Wiggins, Lai, \& Deiters, 2005). For example, using the Burnout Inventory for Athletes (VanYperen, 1997), a unidimensional burnout measure, Lai and Wiggins (2003) found that despite lower overall burnout scores and a lack of significant gender differences, burnout levels of NCAA soccer players increased throughout the season. Using the same burnout measure, Wiggins et al. (2005) found that female college soccer and hockey players who had high trait anxiety had significantly higher overall burnout scores than those with lower trait anxiety. Lastly, Lemyre 
et al. (2006) found that college-level swimmers with negative motivational trends scored significantly higher on all three burnout dimensions of the ABQ (Raedeke \& Smith, 2001) than did those with positive motivational trends (self-determined motivation). In addition, Lemyre et al.'s study (2006) revealed that athletes with higher variability in negative affect were at greater risk of burnout. While important relationships were highlighted within these studies, overall levels of burnout and links between burnout and other variables, such as year of study or academic program, were not examined. Furthermore, the samples within the studies conducted by Lai and Wiggins (2003), Lemyre et al. (2006), and Wiggins and colleagues $(2005)$ were relatively small $(\mathrm{N}<90)$ and were limited to American NCAA athletes.

Overall, the findings presented thus far help us understand that stress and burnout can occur in sport and academia. While there seems to be considerable empirical evidence regarding factors that contribute to and result from stress and burnout in these settings, there is still a lack of data pertaining to levels of burnout, particularly for a unique subset of individuals withstanding numerous demands - that is, student-athletes. This provided the rationale for conducting the current study, which is part of a larger study assessing the impact of an intervention conducted with university student-athletes experiencing burnout.

\section{Purpose of the Study and Hypotheses}

The purpose of the study was to answer the following research questions and test the following hypotheses:

a. What is the level of burnout among a sample of university student-athletes at two Canadian universities? We hypothesized that moderate levels of burnout would be reported by many participants, with less than $10 \%$ reporting high levels of burnout (Gustafsson et al., 2007).

b. (b) Are there significant differences in burnout levels as they relate to the following factors?

i. Gender: We hypothesized that female student-athletes would report higher levels of burnout than their male counterparts (Cremades et al., 2008; Heidari, 2013).

ii. Sport: Given that demands and social support can vary across sports, we hypothesized that there would be significant differences in levels of burnout between sports (Gustafsson et al., 2008).

iii. Year of university sport participation: We hypothesized that athletes with three or more years of sport experience would have the highest levels of burnout (Grobbelarr et al., 2010).

iv. Academic year: We hypothesized that those in the first year of their academic program would report the highest levels of burnout (Adlaf et al., 2001; Misra \& McKean, 2000; Rawson, Bloomer, \& Kendall, 2001).

v. Academic program: Although no research has addressed burnout in relation to university student-athletes' academic programs, we hypothesized that students pursuing programs related to biophysical sciences, which typically involve more demands due to laboratories, would experience higher levels of burnout than students enrolled in social sciences and humanities programs. 


\section{Methods}

\section{Participants}

The participants were student-athletes $(N=145$; female $=62$, male $=83$; age $17-27$, $M=20.4$ years; $S D=2.07$ ) competing on recognized Canadian Interuniversity Sport teams from two different Ontario universities (University 1, $n=83$; University 2, $n=62$ ). The sample included undergraduates from first $(n=55)$, second $(n=35)$, third $(n=26)$, and fourth years $(n=24)$, as well as Masters $(n=2)$ and $\operatorname{PhD}(n=3)$ student-athletes. With regards to the number of years of university sport participation, the student-athletes ranged from rookies to veterans. Specifically, they were in their first $(n=63)$, second $(n=$ $35)$, third $(n=26)$, fourth $(n=18)$, or fifth year $(n=3)$ of university sport eligibility. Given that this study was part of a larger research project assessing the impact of a seasonlong intervention with selected athletes experiencing burnout, the sample was limited to athletes whose sport season lasted a minimum of five months. Specifically, the athletes participated in university-level hockey $(n=78)$, basketball $(n=36)$, swimming $(n=11)$, volleyball $(n=10)$, or fencing $(n=10)$. The participants' program of study was divided into five categories: (a) math/science $(n=16)$, (b) health sciences $(n=26)$, (c) commerce $(n=27)$, (d) communication $(n=14)$, and (e) social studies $(n=59)$. The first two were related to biophysical sciences, while the latter three were considered social sciences and humanities programs.

\section{Instrument}

The athletes' level of burnout was assessed using the ABQ (Raedeke \& Smith, 2001), a 15 -item self-report instrument comprising three five-item subscales (i.e., emotional and physical exhaustion, reduced personal accomplishment, and sport devaluation). The items stemmed from the question "How often do you feel this way?" and were scored on a five-point Likert scale ranging from one (almost never) to five (almost always). The $\mathrm{ABQ}$ was chosen as a burnout measure due to its acceptable psychometric properties and its predominant use to assess burnout in sport (Cresswell \& Eklund, 2007; Dubuc et al., 2010; Gustafsson et al., 2008; Hodge et al., 2008; Lemyre et al., 2006). Raedeke and Smith (2001) reported that the internal consistency of the subscales exceeds .70 and testretest reliability coefficients range from .86 to .92 on the three subscales.

Raedeke and Smith (2001) did not provide clear cut-off scores for the ABQ. However, a cluster analysis conducted with a sample of swimmers (Raedeke, 1997), and scores from a comparative occupational questionnaire (MBI-GS; Maslach et al., 1996), suggest that individuals considered to have high levels of burnout typically have scores near or above the mean score of three on all three subscales. While Eklund and Cresswell (2007) suggested that similar cut-off scores be used to identify high levels of sport burnout with the ABQ, Hodge and colleagues (2008) stated that athletes in Raedeke's (1997) study having high overall burnout scores had reduced sense of accomplishment subscores lower than three; hence, Hodge et al. used a lower reduced accomplishment cut-off score of 2.7 in their study. Nevertheless, in the current study, we attempted to remain cautious about categorizing athletes into a high burnout group, and therefore used ABQ scores of three or higher on all three subscales as the cut-off to identify high burnout levels. Previous 
studies have proposed that burnout symptoms may arise sequentially. For example, some researchers suggested that exhaustion may lead to reduced personal accomplishment, which can, over time, cause sport devaluation (Cresswell \& Eklund, 2006; Goodger et al., 2007; Gustafsson et al., 2008). Hence, a mean score of three or higher on two of the ABQ subscales was used in the current study to identify moderate levels of burnout among student-athletes.

\section{Procedures}

The primary researcher contacted coaches from eligible men's and women's teams at both universities prior to the season in order to seek their teams' participation in the study. Approximately one month following the start of the academic year, the researcher met with teams who agreed to participate, to allow the students to become fully immersed in the semester and their sport season. During each 20-minute meeting, the participants were first given a verbal explanation of the purpose of the study and the requirements to partake in it. Next, they signed the consent form approved by the Ethics Boards from both universities. Finally, they completed the ABQ and a short demographic questionnaire and submitted these directly to the researcher.

\section{Data Analysis}

To test the proposed hypotheses, several statistical analyses were conducted. First, internal consistency estimates were obtained to verify the reliability of the subscales. Then, mean burnout scores and standard deviations were computed for each burnout subscale to determine the student-athletes' burnout levels. Correlations between each of these subscales were then examined to assess how the ABQ's distinct subscales relate to one another. Next, a chi-square goodness-of-fit test was performed to test whether the hypothesized number of athletes experiencing a high level of burnout was reflected within the current sample. Lastly, a series of one-way between-subject ANOVAs and independent t-tests were computed to identify and further examine any significant differences in burnout levels. To determine whether these analyses had sufficient power to detect meaningful effects, a post hoc power analysis was conducted.

\section{Results}

The internal consistency estimates for the ABQ were excellent, exceeding Nunally and Bernstein's (1994) recommended criterion of 0.70. The alpha value for the global scales was 0.86 , while it was $0.82,0.81$, and 0.87 for the subscales of emotional and physical exhaustion, reduced accomplishment, and devaluation, respectively.

Average burnout scores out of a possible score of 5 were computed for each of the ABQ's subscales. The mean scores for emotional and physical exhaustion, reduced personal accomplishment, and sport devaluation were $2.77(S D=.75), 2.28(S D=.71)$, and $1.90(S D=.80)$, respectively. Overall, these mean scores assessed during the earlier part of the student-athletes' season can be considered low to moderate; they reflect values between "rarely" and "sometimes." When comparing them with early-season burnout scores from Cresswell and Eklund's (2006) study of professional rugby players competing over a similar 30-week season, the university student-athletes' scores were slightly higher 
for each burnout dimension. In addition, 1.4\% of the student-athletes $(n=2)$ scored 3 or higher on all three of the burnout subscales and were thus experiencing burnout symptoms anywhere from "sometimes" to "almost all the time." A chi-square test of goodnessof-fit was performed using unequal ratios to reflect the aforementioned hypothesis. Significant results $\mathrm{x}^{2}(2, \mathrm{~N}=145)=14.04, \mathrm{p}=0.001$ suggest that participants fell within the expected categories. As such, these findings support the hypothesis that less than $10 \%$ of the student-athletes would experience high levels of burnout, as defined by Raedeke (1997) and Eklund and Cresswell (2007).

While few student-athletes scored high on all three burnout dimensions, $18 \%(\mathrm{n}=26)$ of them scored 3 or higher on two of the three burnout subscales, which suggests that they may have been experiencing moderate levels of burnout or early phases of burnout. More specifically, 17 participants scored 3 or higher on reduced accomplishment and emotional and physical exhaustion, seven had scores of 3 or higher on the devaluation and emotional and physical exhaustion subscales, and three participants scored 3 or higher on the devaluation and reduced accomplishment subscales. Interestingly, when examining each burnout dimension individually for scores of 3 or higher, results revealed that nearly 50\% of the student-athletes $(\mathrm{n}=71)$ reported high levels of emotional and physical exhaustion, $18 \%(n=26)$ had high levels of reduced accomplishment, and $11 \%(n=16)$ reported elevated devaluation scores.

Correlational statistics show that all three burnout subscales scores were significantly related, as indicated in Table 1, which supports previous findings put forth by Cresswell and Eklund (2005) and Lemyre et al. (2008).

Table 1

Correlations between $A B Q$ subscales

\begin{tabular}{lccc}
\hline Subscale & 1 & 2 & 3 \\
\hline 1. Exhaustion & 1.00 & $.28^{* *}$ & $.29^{* *}$ \\
2. Reduced Sense of Accomplishment & $.28^{* *}$ & 1.00 & $.46^{* *}$ \\
3. Sport Devaluation & $.29^{* *}$ & $.46^{* *}$ & 1.00 \\
\hline
\end{tabular}

Note: Significant at $\mathrm{p}<.01$ (two-tailed)

A series of one-way between-subject ANOVAs were conducted to examine the effects of the various independent variables (i.e., gender, sport, year of university sport participation, academic year, and academic program) on burnout levels. There were no significant effects at the $\mathrm{p}<.05$ level for academic year on emotional and physical exhaustion, $F(5$, $139)=1.60, p=0.16$, reduced sense of accomplishment, $F(5,139)=0.71, p=0.62$, and sport devaluation, $F(5,139)=0.64, p=0.67$. Similarly, there were no significant effects for academic program on emotional and physical exhaustion, $F(4,137)=1.22, p=0.31$, reduced sense of accomplishment, $F(4,137)=1.36, p=0.25$, and sport devaluation, $F(4$, $137)=0.41, p=0.80$. Lastly, no significant differences emerged with regards to years of 
university sport participation and level of emotional and physical exhaustion, $F(4,140)$ $=1.20, p=0.31$, reduced sense of accomplishment, $F(4,140)=1.09, p=0.37$, and sport devaluation, $F(4,140)=0.27, p=0.90$. Results therefore do not support our hypotheses that there would be significant differences in the burnout levels of student-athletes based on their academic year, academic program, and year of university sport participation.

However, significant differences pertaining to gender did emerge. Specifically, independent t-tests revealed a significant difference between the scores of the male $(M=2.59$, $S D=0.75)$ and female student-athletes $(M=2.91, S D=0.75), t(143)=2.49, p=0.01$, $d=-0.43$, on the emotional and physical exhaustion subscale. The latter value represents a small to medium effect size, based on Cohen's recommended values (1988). A post hoc power analysis computed using an alpha $=0.05$ indicated an observed power of 0.799 , suggesting that there was approximately an $80 \%$ chance of detecting the effect. There were no significant differences in the male and female student-athletes' reduced sense of accomplishment scores, male $(M=2.20, S D=0.67)$, female $(M=2.33, S D=0.73), t$ $(143)=1.10, p=0.27$, and sport devaluation scores, male $(M=1.90, S D=0.79)$, female $(M=1.91, S D=0.82), t(143)=0.10, p=0.92$. This provides partial support to the genderrelated hypothesis.

Significant differences also emerged when examining the effects of sport on all three burnout subscales, which supports our hypothesis. Specifically, results revealed significant effects of sport on emotional and physical exhaustion, $F(4,140)=6.17, p<0.001$, $\mathrm{n}^{2}=0.150$, reduced sense of accomplishment $F(4,140)=3.53, p=0.009, \mathrm{n}^{2}=0.092$, and sport devaluation scores, $F(4,140)=3.19, p=0.015, \mathrm{n}^{2}=0.083$. The power of the main effects was 0.311 for emotional and physical exhaustion, 0.170 for reduced sense of accomplishment, and 0.160 for sport devaluation. Post hoc analyses using the Tukey post hoc criterion for significance indicated that average emotional and physical exhaustion scores were significantly lower for hockey players $(M=2.65, S D=0.70)$ and for fencers $(M=2.08, S D=0.81)$ compared to basketball players $(M=3.04, S D=0.69)$ and swimmers $(M=3.36, S D=0.77)$. It was also found that hockey $(M=1.90, S D=0.82)$ and volleyball $(M=1.40, S D=0.52)$ players had significantly lower levels of sport devaluation than fencers $(M=2.62, S D=0.80)$. No significant differences emerged in the post hoc analyses when comparing levels of reduced accomplishment across sports.

\section{Discussion}

The purpose of this study was to examine burnout levels among a sample of studentathletes from two Canadian universities. Overall, results revealed that few of the participants were experiencing high levels of burnout at the time the data were collected. In fact, athlete burnout - characterized by high levels of emotional and physical exhaustion, a reduced sense of accomplishment, and sport devaluation (Raedeke, 1997) - was experienced by less than $2 \%$ of the student-athletes, which is consistent with previous findings (Gustafsson et al., 2007). However, the fact that several student-athletes scored greater than 3 out of 5 on two of the three burnout subscales should be cause for concern, given that data were collected early in the academic year and sport season, at which point demands were not likely at their peak. Researchers suggest that emotional and physical exhaustion and a reduced sense of accomplishment are the first two symptoms to emerge

in the development of burnout (Cresswell \& Eklund, 2006; Kenttä \& Hassmén, 1998). As 
such, higher mean scores on these two subscales by close to one-fifth of the participants in the current study could potentially indicate that they were experiencing an early stage of burnout. Given the negative consequences associated with burnout - including illness (Cresswell \& Eklund, 2006; Gould et al., 1996, 1997), injury (Cresswell \& Eklund 2005, 2006) amotivation (Cresswell \& Eklund, 2005, 2006; Gould et al., 1996; Lemyre et al., 2006), mood disturbances (Cresswell \& Eklund, 2006; Gustafsson et al., 2008), and potential withdrawal from sport (Smith, 1986) - it would be important to continue investigating burnout levels within this population to determine whether or not the prevalence remains the same throughout student-athletes' academic year and the competitive season. Furthermore, given the mental health crisis across university campuses reported by the Canadian Association of College and University Student Services (MacKean, 2011) and the American College Health Association (2009), researchers should correlate student-athletes' levels of burnout with other health-related variables to determine whether those with moderate to high levels of burnout experience additional mental health issues.

When one takes a closer look at the effects of specific demographic variables on burnout, the lack of statistical significance associated with the type of academic program suggests that the academic demands from the student-athletes' different programs did not influence their susceptibility to burnout. Whether they were enrolled in a biophysical sciences program or one pertaining to social sciences and humanities, the participants' levels of emotional and physical exhaustion, reduced sense of accomplishment, and sport devaluation did not significantly vary. With regards to academic year of study, there were no significant differences either; thus, our hypothesis was not supported. Results appear to support one study with Canadian undergraduate students showing that psychological distress - a broad construct encompassing many symptoms linked to burnout, such as chronic stress, worry, lack of enjoyment, loss of confidence, and a feeling of incompetence - did not vary based on students' academic year (Adlaf et al., 2005). The lack of a significant relationship between burnout and both academic program and year of study may be linked to the finding that some student-athletes with increased academic workloads have developed coping skills to manage their demands (Palmer \& Roger, 2009). Another explanation may be that sport acts as a buffer for student-athletes, helping them to cope with the academic stress they face (Kimball \& Freysinger, 2003).

While it was found in past research that rookies and veteran players in their fourth or fifth year of university sport participation had higher incidences of burnout (Grobbelarr et al., 2010), this finding did not emerge in the current study. It is noteworthy that while 63 student-athletes in the current sample were first-year participants, only 18 were in the fourth year of sport participation. This skewness in the sample could be coincidental or could be due to other factors (e.g., sport or academic-related attrition); thus, more research is warranted to further examine this relationship. Overall, the lack of significant differences suggests that new or experienced student-athletes may develop burnout, which is an important finding for coaches and university professors to consider when helping student-athletes to manage demands and develop adequate resources and coping skills.

It is noteworthy that gender and sport significantly impacted burnout scores in this study. The higher level of emotional and physical exhaustion reported by the female student-athletes compared to their male counterparts was also found by Cremades and colleagues (2008). Although more research is warranted to replicate this finding, it is 
relevant to encourage leaders in sport and academia to provide resources, training, and recovery programs that are tailored for women and monitored, to reduce female studentathletes' risk of emotional and physical exhaustion and possible subsequent burnout.

With regards to the various sports, significantly higher levels of emotional and physical exhaustion were found among swimmers and basketball players in the current study, and higher levels of sport devaluation were found among fencers, which does support our hypothesis. We had hypothesized that there would be significant differences between burnout levels across sports, and the results suggest that certain dimensions of burnout may be more pronounced within particular sport environments. Interestingly, Lemyre and colleagues (2006) also reported that university swimmers had high levels of emotional and physical exhaustion, so it may be valuable for coaches to pay particular attention to athletes' emotions and levels of energy in this sport. Given the strong correlation between the burnout subscales, the fencers' high levels of sport devaluation is of interest, especially given that they had relatively low to average scores for emotional and physical exhaustion and reduced sense of accomplishment. This could mean that while the fencers may have felt that they had emotional and physical the energy to meet their sport demands and maintain performance levels, they cared much less about their participation within the sport. There is a lack of research regarding the impact of different sports and associated demands and resources on burnout; thus, these results must be interpreted with caution, and additional studies are warranted.

While this study has generated findings that can inform future research and applied practice, it is important to recognize that it is not without shortcomings. First, as previously stated, because this study was part of a larger research project, burnout scores could not be collected multiple times, which limits the possibility of examining longitudinal trends. Also, having to restrict eligibility to those student-athletes participating in sports with longer seasons, in addition to having to obtain consent from individual coaches, restricted the number of participants and sports included in the study. This may also have led to a skewed representation of certain sports - for example, hockey, from which participants represented over one-third of the overall sample. In addition, given the smaller number of accessible graduate students, the number of student-athletes competing in their fifth athletic season or who were studying at the Master's or PhD level was limited, which has led to an underrepresentation of these groups within the sample. Furthermore, data were collected from two Canadian universities in the same area, which limits geographical representation. While the sample included more participants than in other studies focusing on the burnout of student-athletes (Lai \& Wiggins, 2003; Lemyre et al., 2006; Wiggins et al., 2005), results cannot be generalized to the entire population. Lastly, given that cut-off scores are not provided for the ABQ (Raedeke \& Smith, 2001), and little consensus has been achieved in determining appropriate cut-off criteria, results must be interpreted with caution. Nonetheless, this study serves as a base to inform future studies examining levels of burnout among other Canadian university student-athletes. It would be important to determine whether the findings of this study can be replicated with other samples.

\section{Conclusion and Practical Implications}

In conclusion, while most university student-athletes in this study had low to moderate burnout levels, some of the participants appeared to be experiencing burnout as early 
as one month following the start of the academic and athletic year. This supports research suggesting that student-athletes are at risk of developing burnout. While the year and type of academic program and the year of university sport participation do not appear to have a significant effect on the burnout levels of student-athletes, results suggest that female athletes are more at risk of emotional and physical exhaustion than male athletes. Furthermore, sport should be considered when examining burnout among student-athletes, as swimmers and basketball players reported high levels of emotional and physical exhaustion compared to hockey players and fencers, and fencers had greater levels of sport devaluation than hockey and volleyball players.

Given the aforementioned findings and the many negative consequences associated with burnout, we encourage coaches and other individuals influencing the performance and experience of student-athletes (e.g., professors, administrators, mentors, and counsellors) to assess and monitor the demands placed on student-athletes, their resources and coping skills, as well as their stress and burnout levels whenever possible. There are many tools that student-athletes could be taught to use to gauge their levels and seek additional support when necessary to ensure academic success and prolonged sport participation. In our view, one burnout case is one too many. Being proactive and empowering student-athletes to develop effective self-regulation skills that could allow them to adapt and meet stressful demands may be an important step in reducing the levels and risks of athlete burnout.

\section{References}

Adlaf, E. M., Demers, A., \& Gliksman, L. (2005). Canadian Campus Survey 2004. Toronto, Canada: Centre for Addiction and Mental Health.

Adlaf, E. M., Gliksman, L., Demers, A., \& Newton-Taylor, B. (2001). The prevalence of elevated psychological distress among Canadian undergraduates: Findings from the 1998 Canadian Campus Survey. Journal of American College Health, 5O, 67-72.

American College Health Association (2009). American College Health Association: National College Health Assessment II: Reference group data report, spring 2009. Linthicum, MD: American College Health Association.

Aries, E., McCarthy, D., Salovey, P., \& Banaji, M. R. (2004). A comparison of athletes and non-athletes at highly selective colleges: Academic performance and personal development. Research in Higher Education, 45, 577-602.

Borden, V. M. H., \& Young, J. W. (2008). Measurement validity and accountability for student learning. New Directions for Institutional Research, S1, 19-37.

Campbell, R. L., Svenson, L., \& Jarvis, G. (1992). Perceived level of stress among university undergraduate students in Edmonton, Canada. Perceptual and Motor Skills, $75,552-554$.

Coakley, J. (1992). Burnout among adolescent athletes: A personal failure or social problem? Sociology of Sport Journal, 9, 271-285.

Coakley, J. (2009). From the outside in: Burnout as an organizational issue. Journal of Intercollegiate Sports, 2, 35-41. 
Cohen, J. (1988). Statistical power analysis for the behavioral sciences (2nd ed.). Hillsdale, NJ: Erlbaum.

Cremades, J. G., University, B., \& Wiggins, M. S. (2008). Direction and intensity of trait anxiety as predictors of burnout among collegiate athletes. Athletic Insight, 10. Retrieved from http://www.athleticinsight.com/Vol1oIss2/TraitAnxiety.htm

Cresswell, S. L., \& Eklund, R. C. (2005). Motivation and burnout among top amateur rugby players. Medicine \& Science in Sports \& Exercise, 37, 469-477.

Cresswell, S. L., \& Eklund, R. C. (2006). The nature of player burnout in rugby: Key characteristics and attributions. Journal of Applied Sport Psychology, 18, 219-239.

Cresswell, S. L., \& Eklund, R. C. (2007). Athlete burnout: A longitudinal qualitative study. The Sport Psychologist, 21, 1-20.

Dubuc, N. G., Schinke, R. S., Eys, M. A., Battochio, R., \& Zaichowsky, L. (2010). Experiences of burnout among adolescent female gymnasts: Three case studies. Journal of Clinical Sport Psychology, 4, 1-18.

Eades, A. (1991). An investigation of burnout in intercollegiate athletes: The development of the Eades Athletic Burnout Inventory. Paper presented at the National Conference of the North American Society for the Psychology of Sport and Physical Activity, Asilomar, CA.

Eklund, R. C., \& Cresswell, S. L. (2007). Athlete burnout. In G. Tenenbaum \& R. C. Eklund (Eds.), Handbook of sport psychology (pp. 621-641). Hoboken, NJ: Wiley.

Freudenberger, H. J. (1974). Staff burnout. Journal of Social Science, 30, 159-165.

Goodger, K., Wolfenden, L., \& Lavallee, D. (2007). Symptoms and consequences associated with three dimensions of burnout in junior tennis players. International Journal of Sport Psychology, 38, 342-364.

Gould, D., Tuffey, S., Udry, E., \& Loehr, J. (1996). Burnout in competitive junior tennis players: II. Qualitative analysis. The Sport Psychologist, 10, 341-366.

Gould, D., Tuffey, S., Udry, E., \& Loehr, J. (1997). Burnout in competitive junior tennis players: III. Individual differences in the burnout experience. The Sport Psychologist, 11, 257-276.

Gould, D., \& Whitley, M. A. (2009). Sources and consequences of athletic burnout among college athletes. Journal of Intercollegiate Sports, 2, 16-30.

Grobbelarr, H. W., Malan, D. J. D., Steyn, B. J. M., \& Ellis, S. M. (2010). Factors affecting the recovery-stress, burnout, and mood state scores of elite student rugby players. South African Journal for Research in Sport, Physical Education and Recreation, 32, 41-54.

Gustafsson, H., Hassmén, P., Kenttä, G., \& Johansson, M. (2008). A qualitative analysis of burnout in elite Swedish athletes. Psychology of Sport and Exercise, 9, 800-816.

Gustafsson, H., Kenttä, G., \& Hassmén, P. (2011). Athlete burnout: An integrated model and future research directions. International Review of Sport and Exercise Psychology, $4,3^{-24}$. 
Gustafsson, H., Kenttä, G., Hassmén, P., \& Lundqvist, C. (2007). Prevalence of burnout in competitive adolescent athletes. The Sport Psychologist, 21, 21-37.

Heidari, S. (2013). Gender differences in burnout in individual athletes. European Journal of Experimental Biology, 3, 583-588.

Hodge, K., Lonsdale, C., \& Ng, J. Y. (2008). Burnout in elite rugby: Relationships with basic psychological needs fulfilment. Journal of Sports Sciences, 26, 835-844.

Kenttä, G., \& Hassmén, P. (1998). Overtraining and recovery: A conceptual model. Sports Medicine, 26, 1-16.

Kimball, A., \& Freysinger, V. (2003). Leisure, stress, and coping: The sport participation of collegiate student-athletes. Leisure Sciences, 25, 115-141.

Lai, C., \& Wiggins, M. S. (2003). Burnout perceptions over time in NCAA Division I soccer players. International Sports Journal, 7, 120-127.

Lazarus, R. S. (1966). Psychological stress and the coping process. New York, NY: McGraw-Hill.

Lazarus, R. S. (1982). Thoughts on the relation between emotion and cognition. American Psychologist, 37, 1019-1024.

Lemyre, P-N., Hall, H. K., \& Roberts, G. C. (2008). A social cognitive approach to burnout in elite athletes. Scandinavian Journal of Medicine and Science in Sports, 18, 221-234.

Lemyre, P-N., Treasure, P. C., \& Roberts, G. C. (2006). Influence of variability in motivation and affect on elite athlete burnout susceptibility. Journal of Sport and Exercise Psychology, 28, 32-48.

MacKean, G. (2011). Mental health and well-being in post-secondary education settings: A literature and environmental scan to support planning and action in Canada. Canadian Association of College and University Student Services and Canadian Mental Health Association. Retrieved from http://www.cacuss.ca/_Library/documents/Post_ Sec_Final_Report_June6.pdf

Maslach, C., \& Jackson, S. E. (1981). The measurement of experienced burnout. Journal of Occupational Behavior, 2, 99-113.

Maslach, C., Jackson, S. E., \& Leiter, M. P. (1996). Maslach Burnout Inventory manual (3rd ed.). Palo Alto, CA: Consulting Psychologists Press.

Miller, P. S., \& Kerr, G. (2002). The athletic, academic and social experiences of intercollegiate student-athletes. Journal of Sport Behavior, 25, 346-367.

Misra, R. \& McKean, M. (2000). College students' academic stress and its relation to their anxiety, time management, and leisure satisfaction. American Journal of Health Studies, 16, 41-51.

Morgan, W. P., Brown, D. R., Raglin, J. S., O’Conner, P. J., \& Ellickson, K. A. (1987). Psychological monitoring of overtraining and staleness. British Journal of Sport Medicine, 21, 107-114. 
Nunnally, J. C., \& Bernstein, I. H. (1994). Psychometric theory (3rd ed.). New York, NY: McGraw-Hill.

Palmer, A., \& Roger, S. (2009). Mindfulness, stress, and coping among university students Canadian Journal of Counselling, 43, 198-212.

Perreault, S., Gaudreau, P., Lapointe, M-C., \& Lacroix, C. (2007). Does it take three to tango? Psychological need satisfaction and athlete burnout. International Journal of Sport Psychology, 38, 437-450.

Raedeke, T., \& Smith, A. L. (2004). Coping resources and athlete burnout: An examination of stress mediated and moderation hypotheses. Journal of Sport \& Exercise Psychology, 26, 525-541.

Raedeke, T. D. (1997). Is athlete burnout more than just stress? A sport commitment perspective. Journal of Sport and Exercise Psychology, 19, 396-417.

Raedeke, T. D., \& Smith, R. E. (2001). Development and preliminary validation of an athlete burnout measure. Journal of Sport and Exercise Psychology, 23, 281-306.

Rawson, H. E., Bloomer, K., \& Kendall, A. (2001). Stress, anxiety, depression, and physical illness in college students. The Journal of Genetic Psychology, 155, 321-330.

Salanova, M., Schaufeli, W., Martinez, I., \& Breso, E. (2010) How obstacles and facilitators predict academic performance: The mediating role of study burnout and engagement. Anxiety, Stress, \& Coping, 23, 53-70.

Salmela-Aro, K., Noona, K., Pietikäinen, M., \& Jokela, J. (2008). Does school matter? The role of school context in adolescents' school-related burnout. European Psychologist, 13, 12-23.

Schmidt, G. W., \& Stein, G. L. (1991). Sport commitment: A model integrating enjoyment, dropout, and burnout. Journal of Sport \& Exercise Psychology, 8, 254-265.

Silva, J. M. (1990). An analysis of the training stress syndrome in competitive athletics. Journal of Applied Sport Psychology, 2, 5-20.

Smith, R. E. (1986). Toward a cognitive-affective model of athletic burnout. Journal of Sport Psychology, 8, 36-50.

VanYperen, W. (1997). Inequity and vulnerability to dropout symptoms: An exploratory causal analysis among highly skilled young soccer players. The Sport Psychologist, 11, $318-325$.

Wiggins, M. S., Lai, C., \& Deiters, J. A. (2005). Anxiety and burnout in female collegiate ice hockey and soccer athletes. Perceptual and Motor Skills, 101, 519-524.

Wilson Van Hooris, C. R., \& Morgan, B. L. (2007). Understanding power and rules of thumb for determining sample size. Tutorials in Quantitative Methods for Psychology, $3,43-50$. 


\section{Contact Information}

Nicole Dubuc-Charbonneau

Human Kinetics

University of Ottawa

ngdubuc@gmail.com

Nicole Dubuc-Charbonneau is a doctoral student in Human Kinetics at the University of Ottawa and works as a mental performance consultant with competitive athletes from various sports. To date, her research has focused on athlete burnout. By bridging research and applied practice, she also seeks to explore the influence of stress, adaptation, and selfregulation on student well-being and performance. She has presented several papers at international conferences and published five peer-reviewed articles.

Natalie Durand-Bush is an Associate Professor in the School of Human Kinetics at the University of Ottawa. She has been the School Assistant Director of Undergraduate Studies and Student Affairs for the past three years. Through her research, she aims to understand the self-regulatory processes and skills underlying the development of optimal performance and well-being in different contexts, including sport, medicine, the performing arts, and academia. She also investigates mental training interventions designed to help individuals achieve performance excellence and cope with stress and burnout. She has presented over 130 papers at conferences and published 25 peer-reviewed articles, four book chapters, and a life-skills workbook.

Dr. Tanya Forneris is an Associate Professor in the School of Human Kinetics at the University of Ottawa. She received her PhD in Counselling Psychology from Virginia Commonwealth University. Tanya's expertise is in positive youth development and community programming. More specifically, her research focuses on the development, implementation, and evaluation of life skills-based sport and physical activity programs to enhance youth development, particularly with marginalized populations. She has worked with non-profit organizations such as the Boys and Girls Club, and she has also worked internationally with an NGO in Nepal. 